\title{
PEOPLING OF WESTERN JAPAN, FOCUSING ON KYUSHU, SHIKOKU, AND RYUKYU ARCHIPELAGO
}

\author{
Hiroto Takamiya \\ Sapporo University, 3-7 Nishioka, Toyohira-ku, Sapporo 062-8520, Japan. Email: takamiya@ sapporo-u.ac.jp. \\ Hiromi Obata \\ Maizo Bunka zai Chosa-shitsu, Kumamoto University, 2-39-1 Kurokami, Kumamoto City 860-8555, Japan
}

\begin{abstract}
The discovery of the Iwajuku site in Japan is the beginning of the study of the first Paleolithic cultures in the region. In this paper we examine the timing of the earliest colonization of southern Japan, especially focusing on the areas of Kyushu, Shikoku, and the Ryukyu archipelago. Osteological studies have proposed the ultimate origin of these western Japanese Paleolithic populations in Southeast Asia. If this hypothesis is correct, Native Americans may be remotely related to the populations of this region. Greater attention to data from areas such as Japan is necessary to understand the timing and nature of New World colonization.
\end{abstract}

\section{INTRODOUCTION}

Homo sapiens sapiens did not evolve in the region now known as Japan. They, and possibly archaic hominids at some point in time, migrated from the nearby continent to the Japanese islands. It was not until 1949 that Pleistocene human occupation of Japan was recognized, most notably at the Iwajuku site (Aizawa 1969). Before this discovery, most archaeologists believed that the Japanese islands were colonized at the beginning of the Jomon period (Early Neolithic), arguing that the region was inhospitable during the Pleistocene due to active volcanism. The discovery of the Iwajuku site not only proved the presence of the Paleolithic cultures in this region, but also suggested the next question: When did earliest human colonization occur?

The examination of the timing of human colonization to Japan is extremely important not only for the prehistory of the region, but also that of the New World. Data from Japan may provide clues as to the possibility and nature of early archaeological sites in the New World. Here, we examine the timing of colonization of western Japan, focusing especially on Kyushu, Shikoku, and the Ryukyu archipelago. This geographic focus is significant because the peopling of Japan may have taken place through Korea to Kyushu, and/or from farther south through the Ryukyu archipelago to Kyushu. Radiocarbon dates from Paleolithic period sites were collected to assess the timing of colonization of these areas. However, the ages of most Paleolithic sites in the region have been established by relative dating (i.e. tephra stratigraphy) and morphological characteristics of lithic artifacts. Only and handful of sites have been directly ${ }^{14} \mathrm{C}$ dated. Consequently, we provide both a brief introduction to these alternative dating methods and a discussion of the available ${ }^{14} \mathrm{C}$-dated sites. We then examine possible routes through which the Japanese archipelago was colonized, and attempt to relate these observations to the study of the peopling of the New World.

\section{BRIEF BACKGROUND AND RADIOCARBON DATES}

\section{Kyushu Region}

The search for the presence of Paleolithic sites in Kyushu began with the excavation of the Fukui Cave site in 1960 (Serizawa 1976, 1979). By 1965, 42 sites were reported as Paleolithic in age (Kamaki and Makabe 1965). According to Obata and Miyata (1999:55), at least 800 Paleolithic sites are now known from this island alone. Of these, 530 belong to the late Upper Paleolithic and the transition between the Paleolithic and Jomon periods. Most of the Paleolithic sites on Kyushu have been dated stratigraphically in relation to volcanic tephras of known age. Here we describe briefly 
the five tephras used as key age markers for establishing an Upper Paleolithic chronology in Kyushu (Tachibana 2000; Fujimoto 2000). The Aera Caldera, the most important tephra, is dated to between 24,000 and 25,000 BP. The Black Band tephra is estimated to date to approximately 28,000 BP. These two ash layers are widely distributed not only on Kyushu, but also most areas of Japan. The next three ash layers are found only in restricted areas on Kyushu, but are significant in establishing local chronology. The Tane IV tephra is distributed in southern Kyushu and on Tane Island, and dates to 30,000 BP. The distribution of the Kirishima Iwaokoshi (Kr-lw) tephra is limited to Southern and eastern Kyushu, dating also to 30,000 BP. The Kokonoe-Daiichi- Karuishi So (Kjp-1) tephra, dating to 40,000 BP, is found in eastern Kyushu. Finally, the Aso 4 ash layer (Aso-4), dating to $80,000-90,000 \mathrm{BP}$, is an important tephra for establishing Middle Paleolithic chronology (Tachibana 2000:1-3; Fujimoto 2000:12).

Did archaic hominids colonize Kyushu during the Lower or Middle Paleolithic periods? Tachibana (2000) believes that such sites are present but undiscovered because thick ash layers cover the sedimentary deposits of appropriate ages to contain Lower or Middle Paleolithic occurrences (see also Shimaoka 2000). Several sites have been purported to belong to the Middle Paleolithic, such as Tsujita, Yokota, Matsuo, Ushiromuta, and Kamishimoda (Tachibana 2000:3; Shimaoka 2000:9). The first four sites, while yielding lithic assemblages that clearly differ from the Upper Paleolithic, are not associated with tephras of known age and have not yielded chronometric dates. The last site is also said to have produced a Middle Paleolithic-like lithic assemblage. Although the Aso-4 tephra $(80,000-90,000 \mathrm{BP})$ is reported at the site, stratigraphic association between the tephra and archaeological materials is not yet clear. Regarding the early colonization of Kyushu, Obata and Miyata (1999:59) conclude that "the lithic assemblages which are said to date prior to the Upper Paleolithic were collected in isolation or obtained through site excavation, but detailed reports have not been published. In short, they cannot be readily accepted as the Middle and/or Lower Paleolithic sites."

Only one possible Middle Paleolithic assemblage, from Layer 15 at Fukui Cave, is associated with a ${ }^{14} \mathrm{C}$ date. The wood charcoal sample yielded and age of 31,900 BP (Serizawa 1976, 1979; Kawamichi 2000:17; Nakamura et al. 2000). Serizawa first announced that Layer 15 belonged to the Lower Paleolithic, but later suggested that it is Middle Paleolithic (Serizawa 1999 cited from Kawamichi 2000:17).

While the status of the Lower and Middle Paleolithic cultures on Kyushu is still debated, it is clear that initial Upper Paleolithic human populations were present in the region by 30,000 BP. Several sites have yielded radiocarbon dates from this time period. On Kyushu, the Ishinomoto site in Kumamoto prefecture yielded four radiocarbon dates ranging from 33,720 $\pm 430 \mathrm{BP}$ to 31,460 \pm 270 BP (Kumamoto Prefecture Board of Education 1999a). The Ushiromuta site in Miyazaki prefecture has been dated to 29,520 $\pm 180 \mathrm{BP}$ and 29,470 $\pm 150 \mathrm{BP}$ (Shimaoka 2000). Finally, the Kawahara No.14 site in Kumamoto prefecture have yielded ${ }^{14} \mathrm{C}$ dates of $29,370 \pm 360$ BP and $28,790 \pm 350$ BP (Kumamoto University 2000).

Three sites belonging to the early Upper Paleolithic period have been ${ }^{14} \mathrm{C}$ dated. The Chouchi site locating in Kagoshima prefecture has yielded three ${ }^{14} \mathrm{C}$ dates of 22,390 $\pm 1200 \mathrm{BP}, 24,690 \pm 130 \mathrm{BP}$, and 25,110 $\pm 210 \mathrm{BP}$. The Nihongi site, also located in Kagoshima prefecture, has ${ }^{14} \mathrm{C}$ dated to be $25,330 \pm 880$ BP. A date of $24,400 \pm 230$ BP has been obtained from the Hyakkadai site in Nagasaki prefecture.

There are only three sites ${ }^{14} \mathrm{C}$ dated to the late part of the Upper Paleolithic sites. The Kiriki and Mimitori sites are both from Kagoshima prefecture. The former has yielded four ${ }^{14} \mathrm{C}$ dates ranging from $24,270 \pm 180 \mathrm{BP}$ to $22,960 \pm 170 \mathrm{BP}$ (Nagano 2000). Only one sample has been ${ }^{14} \mathrm{C}$ dated from 
the latter, resulted in an age estimate of 24,030 $\pm 110 \mathrm{BP}$ (Nagano 2000). The Mimikiri site, located in Kumamoto prefecture, also has a date of 23,200 \pm 220 BP (Kumamoto Prefecture Board of Education 1999b).

Only two terminal Paleolithic sites have been ${ }^{14} \mathrm{C}$ dated at the present time. The Chaen site in Nagasaki prefecture produced a date of 15,450 \pm 190 BP (Kishiku Town Board of Education 1998). The Fukui Cave site, also in Nagasaki prefecture, contained five terminal Paleolithic cultural layers, with dates ranging from $14,000 \pm 400 \mathrm{BP}$ to $10,700 \pm 300 \mathrm{BP}$. It should be mentioned that Fukui Cave contains the oldest remains of pottery in the world, found in association with microblade cores. Radiocarbon dates place the appearance of ceramic technology at 12,400 $\pm 350 \mathrm{BP}$ and 12,700 \pm 500 (Nakamura et. al 2000).

\section{Shikoku Region}

Fujino (personal communication 2001) estimates that there are 200-300 known Paleolithic sites in Shikoku. This number will certainly grow given that Paleolithic research in the region is in its infancy (Kimura 1994:1). According to Fujino, no Middle Paleolithic or earlier sites are yet known on Shikoku. Rather, the earliest known sites date to the later part of the Upper Paleolithic. Fujino believes, based on his summary of Paleolithic sites in western Japan, that the beginning of the Upper Paleolithic in Shikoku is two or three thousand years later than on Chugoku and Kyushu (Fujino 1999). To best of our knowledge, the only ${ }^{14} \mathrm{C}$ dated site on Shikoku is Kamikuroiwa Rock Shelter in Ehime Prefecture. This site is one of the most important in all of Japan because it covers the transitional period between the Paleolithic and Jomon. The lower layer (Layer IX) yielded tanged points and no pottery. The upper layer (Layer V) produced one of the earliest known assemblages of pottery, associated with arrow points but without tanged points. Importantly, it appears that the transition from the Paleolithic to the Jomon at Kamikuroiwa Rock Shelter occurred later than at Fukui Cave: Layer IX (terminal Paleolithic) at Kamikuroiwa has been ${ }^{14} \mathrm{C}$ dated to $12,165 \pm 650 \mathrm{BP}$ and Layer V (Jomon) to 10,085 \pm 320 BP (Nakamura et al. 2000).

\section{Ryukyu Archipelagos}

The islands linearly distributed between Kyushu and Taiwan are collectively known as the Ryukyu archipelago. The archipelago can be divided into three regions in terms of geological and cultural characteristics: the Northern, Central, and Southern Ryukyus (e.g. Kokubu 1972). Northern Ryukyu consists of Yaku, Tane, and their satellite islands. Central Ryukyu consists of Amami, Okinawa, and their satellite islands. Southern Ryukyu consists of Miyako, Ishigaki and their satellite islands

The presence of Pleistocene human populations in the Ryukyu archipelago was first suggested by Tokunaga as early as 1936 . He recognized that modified deer bones recovered from Gadabaru cave site, in Central Ryukyu, were potentially human artifacts. In the 1960s and 1970s, several additional sites yielded modified deer bones, and were believed to be bone "artifacts" based on Tokunaga's original observation. By 1977, having analyzed these bone "artifacts", Kato (1977) reached conclusion that the modifications were made by deer chewing and not by humans. Most scholars today support Kato's conclusion. This leaves open the question of when humans first colonized Ryukyu.

Central Ryukyu provides earliest evidence for presence of Homo sapiens sapiens during the Late Pleistocene. In 1968, the Yamashita-cho No.1 cave site yielded fragmentary remains of a human child estimated to have been 6 years old at time of death. Unfortunately, the remains of this immature individual provide only limited information on the physical characteristics of the resident human population (Takamiya 1994:327). However, wood charcoal associated with the fossil aston- 
ished the academic community: At 32,000 \pm 650 BP the Yamashita-cho No.1 fossil is the earliest remains of Homo sapiens sapiens in East Asia (Baba and Narasaki 1991; Matsu'ura and Kondo 2000; Takamiya 1983). At about same time, the Minatogawa site yielded human remains representing at least 5 or 6 adult male and female individuals. The analysis of these remains have contributed greatly to our understanding of the origins of the Japanese (Hanihara 1991). The site has been ${ }^{14} \mathrm{C}$ dated to $18,000 \pm 650 \mathrm{BP}$ and 16,600 $\pm 300 \mathrm{BP}$ (Suzuki 1975). In addition, 6 other sites in Central Ryukyu have yielded human skeletal remains (Matsu'ura and Kondo 2000). While the precise ages of these later sites are not known, the radiometric dates from Yamashita-cho No.1 and Minatogawa demonstrate the presence of Homo sapiens sapiens in the region during the late Pleistocene.

In Southern Ryukyu, the only known Pleistocene site is the Pinzaabu site, which produced fossil human remains but no lithic technology. The site has been ${ }^{14} \mathrm{C}$ dated to $25,800 \pm 900 \mathrm{BP}$ and 26,800 $\pm 1,300$ BP (Hamada 1985).

Until recently, very little was known about the Paleolithic in the region North of Okinawa, namely Northern Ryukyu through the Amami archipelago. In 1986, the stone artifacts of clear human manufacture were reported for the first time from the Tsuchihama Yaya site on Amami Island. The site was radiocarbon dated to $>21,400 \mathrm{BP}$ (Kagoshima Prefecture Board of Education 1986). Two years later, the Kishikawa site yielded Paleolithic artifacts with a finite radiocarbon age of 25,250 \pm 790 BP (Tamura and Ikeda 1995). In 1992, the presence of Pliestocene human populations in Northern Ryukyu was demonstrated at the Yokomine $\mathrm{C}$ site, on the Tane island. The site was first excavated by the Minami Tane Town Board of Education in 1992, resulting in a collection of Paleolithic artifacts and three wood charcoal dates of $>30,260 \mathrm{BP},>31,080 \mathrm{BP}$, and >28,110 BP (Minami Tane Town Board of Education 1993). The site was re-excavated in 1995 and 1996 and this time produced four finite ${ }^{14} \mathrm{C}$ ages of $31,280 \pm 690 \mathrm{BP}, 29,670 \pm 540 \mathrm{BP}, 30,490 \pm 590 \mathrm{BP}$, and 29,300 $\pm 520 \mathrm{BP}$ (Minami Tane Town Board of Education 2000). At the Tachikiri site, also on Tane Island, Paleolithic artifacts have been ${ }^{14} \mathrm{C}$ dated to $30,480 \pm 210 \mathrm{BP}$ (Dogome 2000). These lines of evidence demonstrate that Homo sapiens sapiens occupied the Northern Ryukyu archipelago at least as early as the main island of Kyushu.

\section{DISCUSSION}

We conclude that there is as yet no unequivocal Middle (or Lower) Paleolithic site known in Kyushu, Shikoku, or the Ryukyu archipelago. The one possible exception is Layer 15 at Fukui Cave. By approximately 30,000 years ago, however, Homo sapiens sapiens were present on both Kyushu and the Ryukyu archipelago. Shikoku may have been settled from Kyushu or western Chugoku area several thousand years later.

From which region (or regions) were Kyushu and the Ryukyu archipelago colonized? Unfortunately, no human remains dating to the Paleolithic Period have been found on Kyushu. Archaeological data provide the only available information on the origin of Paleolithic Kyushu populations. According to Oda (1999), the early Upper Paleolithic in the region is characterized by "knife type" lithic artifacts. This artifact category seems to be closely related to finds on the Korean Peninsula (Obata and Miyata 2000). Thus, the Korean Peninsula would seem to be the most likely region from where Homo sapiens sapiens spread into Kyushu.

On the other hand, the Ryukyu archipelago, especially Central and Southern Ryukyu, have produced relatively abundant human skeletal remains belonging to the Paleolithic Period. Only 3 sites on mainland Japan have yielded unquestionable Paleolithic human remains, whereas 9 sites in Central and Southern Ryukyu have produced fossilized skeletal remains (Matsu'ura and Kondo 2000). 
While skeletal remains recovered from mainland Japan are all fragmentary, the Minatogawa site in Okinawa has yielded well preserved human remains. Consequently, the Minatogawa remains have been the subject of intensive study and comparisons with other Homo sapiens sapiens fossils from East Asia. The results demonstrate that the Minatogawa populations are morphologically closer to the "Liujin Man" remains from in South China than the Zhoukoudian Upper Cave skeletal remains recovered from Northern China (Hanihara 1991). Accordingly, it has been suggested the Southern and Central Ryukyu regions were populated from the South (Hanihara 1991).

As mentioned above, lithic artifacts belonging to the Paleolithic period have been recovered recently from the Northern and Central Ryukyu regions. Kato (1996) believes that the lithic complex from Northern Ryukyu is affiliated with that found on Kyushu, and the complex from Central Ryukyu with that from Taiwan or further South. Oda (1999) seems to agree with Kato (1996). Okamura (1998) suggests further that the lithic complex represented in Central Ryukyu may have ultimately expanded to Northern Ryukyu. If their analysis is correct, the origin of these Ryukyu Paleolithic populations may be sought in southern areas including Southeast Asia. However, more detailed study of the lithic complexes is necessary to accept this hypothesis (Obata and Miyata 2000).

Archaeological data from Kyushu and Shikoku indicate that once these regions were colonized, about 30,000 years ago, both were continuously occupied into the Holocene (Serizawa 1976). For example, the Fukui Cave site in Kyushu contains an archaeological sequence beginning around $31,900 \mathrm{BP}$ (layer 15) and continuing through the appearance of the earliest pottery in the world at approximately 12,000 BP. These early pottery sherds were associated with formal microblades, which are diagnostic implements of the later part of the Upper Paleolithic period in Japan. The layer below contained only stone artifacts, and the layer above other pottery types and microcores (Serizawa 1976). The Kamikuroiwa Rock Shelter site documents a similar late Upper PaleolithicJomon transition on Shikoku. Together, these sites indicate that Kyushu and Shikoku, once settled, were continuously occupied through to the Jomon period (Serizawa 1976). In contrast, human populations seem to have had a hard time maintaining occupations on the Ryukyu archipelago. There are no sites known from Southern Ryukyu after Pinzaabu until approximately 3000 years ago. In Central Ryukyu, detailed studies of paleogeography and paleodemography have revealed that the Minatogawa and other Paleolithic populations moved out, or died out by the end of the Pleistocene (e.g., Takamiya 1996). Similar phenomena seem to characterize Northern Ryukyu, although further detailed research is needed.

The most important questions issuing from the above presentations are the following: Where did the Paleolithic Japanese populations ultimately originate from? Can anything be said about the peopling of the Americas from this study? As we have discussed, the initial Kyushu Paleolithic populations seem to have originated on the Korean Peninsula, while the contemporaneous Ryukyu populations originated from the South. In an intensive study of Asian populations, Turner (1987) recognized two dental morphology types; a more generalized tooth morphology he terms sundadont, and a more specialized tooth morphology he terms sinodont. The former type is distributed mainly in Southeast Asia and Oceania and the latter in Northeast Asia. He believes that the generalized sundadont morphology is ancestral to contemporary Asian populations. More specifically, as sundadont populations moved north, the more specialized sinodont type emerged (Turner 1987). According to this hypothesis, the ancestors of both Kyushu and Ryukyu Paleolithic populations ultimately originated in Southeast Asia. One group moved from Southeast Asia to the Ryukyu archipelago directly, while the other group first migrated from Southeast to Northeast Asia and then entered Kyushu via the Korean Peninsula. Turner (1987) believes that these Asian populations eventually colonized the New World, implying Southeast Asia is the ultimate point of origin of native Americans. 
Omoto (1999) opposes Turner's hypothesis, disagreeing with the fundamental assumption that things (in this case tooth morphology) necessarily evolve from simple to complex. Omoto (1999) further argues that Turner's conclusion are not supported by genetic data. Omoto and Saitou (1997) have analyzed 26 human groups on the basis of 20 genetic markers. Their results indicate that there is much more diversity among Asians, Pacific Islanders, and Native Americans than previously thought. Like Turner, they suggest the East Asian population can be placed genetically into two groups: Southeast and Northeast Asians. However, Omoto (1999) speculates that these two groups existed in East Asia independently: The former migrated into Southeast Asia through a corridor South of the Himalayas and the latter through a corridor North of the Tibetan massif. Both populations originated in West Asia. Surprisingly enough, the Ainu, who are thought to be the descendants of the Southeast Asian Paleolithic populations by Turner (1987) and Hanihara (1991), belong genetically to Northeast Asian populations (Omoto and Saitou 1997). Thus, the Paleolithic Ryukyu population may have originated in Southeast Asia, while the contemporaneous Kyushu population may have an colonized from independent Northeast Asian population. In this case, Southeast Asians may have nothing to do directly with the origins of native Americans. It would suggest that the focus should be on Northeast Asians to understand the peopling of the New World.

\section{SUMMARY AND CONCLUSION}

This paper has dealt with the peopling of western Japan, more specifically Kyushu, Shikoku, and the Ryukyu archipelago. While several hundred Paleolithic sites have been identified in Kyushu and Shikoku, only a handful of these sites have been ${ }^{14} \mathrm{C}$ dated. Although some sites on Kyushu are claimed to be Middle Paleolithic period occupations, a consensus has not been obtained. By 30,000 years ago, however, Kyushu and Ryukyu were both settled by Homo sapiens sapiens. Archaeological data indicate that Shikoku was first occupied by human population several thousand years later. In terms of artifact complexes, Kyushu, Northern Ryukyu, and Shikoku seem to belong to the same culture tradition. In contrast, Central Ryukyu — and possibly Southern Ryukyu, though no artifacts has yet been recovered—formed different cultural tradition. The evidence suggests that this cultural tradition is related to regions farther south.

Human skeletal remains belonging to the Paleolithic period are known in detail only from the Central and Southern Ryukyu regions. One of the sites, the Minatogawa site dating to 18,000 years ago, has produced fossil remains very important to understanding the origins of the Japanese (Hanihara 1991; Matsu'ura and Kondo 2000). These remains have been analyzed intensively, resulting in the suggestion that the population represented originated in the South. This result supports suggestions made by some archaeologists including Oda (1999), Kato (1996), and Okamura (1998). While no skeletal remains are known from Kyushu or Shikoku (and Northern Ryukyu according to Obata and Miyata [2000]), lithic assemblages suggest these people may have migrated from the Korean Peninsula.

Osteological studies have proposed the ultimate origin of these western Japanese Paleolithic population in Southeast Asia. If this hypothesis is correct, Native Americans may be remotely related to the populations of this region. Geneticists such as Omoto (1999) reject this hypothesis, however, and suggest a dual structure to East Asian populations, both of which originated in West Asia. The process by which these two groups formed hinges on the separate routes they followed on their way to East Asia. If this hypothesis is correct, the ancestors of native Americans should be genetically more related to Northeast than to Southeast Asians.

While the peopling of the New World has been an important theme in anthropology, investigation of the processes by which colonization occurred has suffered from a lack comparisons across the 
Pacific. Additional data from areas such as Japan is necessary to understand the timing and nature of New World colonization. The fact that much of the ${ }^{14} \mathrm{C}$ data presented in this paper was obtained in recent years indicates that Japanese archaeologists are now more aware and more interested in radiocarbon dating. With increased chronological resolution made possible by continued radiocarbon dating we may soon be able to provide more detailed conclusions about the relationships between the peopling of the Japanese archipelago and the peopling of the New World.

\section{ACKNOWLEDGMENTS}

Dr Fujino from Hiroshima University has provided information on the Paleolithic period in Shikoku Island. Dr Toizumi from Waseda University provided radiocarbon dates from several important sites in Japan, including Kaimkuroiwa Rock Shelter and Fukui Cave. We sincerely thank them. We also thank Drs Yaroslav Kuzmin and P Jeffrey Brantingham for inviting us to contribute to this issue. Finally, we would like to thank archaeologists in Kyushu, Shikoku, and Ryukyu archipelago who have worked hard to obtain the data presented in this paper.

\section{REFERENCES}

Aizawa T. 1969."Iwajuku no Hakken" (The Discovery of the Iwajuku site). Kodansha: Tokyo.

Baba H, Narasaki S. 1991. Minatogawa Man, the oldest type of modern Homo sapiens sapiens in East Asia. Quaternary Research 30:221-30.

Dogome H. 2000. Kagoshima-ken ni okeru Koki Kyusekki jidai bunka no seiritsu (The Emergence of the Upper Paleolithic Period and Culture in Kagoshima Prefecture). Kyushu Bunka Kenkyukai, editor. Kumamoto: Kyushu Bunka Kenkyukai. p 23-8.

Fujimoto M. 2000. Miyazaki-ken Ushiromuta Iseki Gakujutsu Chosa (On the excavation of the Ushiromuta site, Miyazaki). Kyushu Bunka Kenkyukai, editor. Kumamoto: Kyushu Bunka Kenkyukai. p 9-11.

Fujino T. 1999. Hiroshima-ken ni okeru Kyusekkijidai Sekkigun (The Paleolithic Stone Assemblages in Hiroshima Prefecture). In: Geibi Tomo no Kai, editor. Kokogaku kara mita Chiiki Bunka. Hiroshima: Keisuisha. p 9-30.

Hanihara K. 1991. Dual structure model for the population history of the Japanese. Japan Review 2:1-33.

Hamada T. 1985. ${ }^{14} \mathrm{C}$ Nendai Sokutei (The radiocarbon dates). In: Pinzaabu, editor. Okinawa Okinawa: Prefecture Board of Education. 180 p.

Kagoshima Prefecture Board of Education. 1988. Tsuchihama Yaya Iseki (The Tsuchihama Yaya site). Kagoshima: Kagoshima Prefecture Board of Education.

Kamaki Y, Makabe T. 1965. Kyushu Chihou no Sen-doki Jidai (The Pre-Ceramic Ages in Kyushu Region). In: Sugihara S, editor. Nihon no Kokogaku. Tokyo: Kawaide-shobo. p 303-22.

Kato S. 1977. Okinawa no Iwayuru Sajo Kokki (On socalled fork shaped bone artifacts from Okinawa). Kokogaku Janaru 167:72-5.

Kato S. 1996. Nansei Shotou eno Kyusekki Bunka no Kakusan (On the dispersion of Paleolithic culture to the Southwest Islands). Journal of Geography 105(3): 372-83.

Kawamichi H. 2000. Nagasaki-ken ni okeru AT kai Sekkigun (The Lithic assemblages below the AT ash layer in Nagasaki Prefecture). In: Kyshu Bunka Kenkyukai, editor. Kyushuni okeru Kyusekki Jidai no Seiritsu. Kumamoto: Kyushu Kyusekki Bunka Kenkyu Kai. p 1722.

Kimura T. 1994. Kouchi-ken no Kyusekki-nansei Shikoku wo Chushin to shite (The Paleolithic in Kouchi Prefecture, focusing on southwestern Shikoku). In: Chu/Shikoku Kyusekki Bunka Danwa Kai, editor. Kochi: Chu/Shikoku Kyusekki Bunka Danwa Kai. p 1-3.

Kishiku Town Board of Education. 1998. Chaen Iseki (The Chaen Site). Nagasaki: Kishiku Town Board of Education.

Kokubu N. 1972. Nanto Senshi Jidai no Kenkyu (Research on the Prehistoric Southern Islands). Tokyo: Keiyu-sha.

Kumamoto Prefocture Board of Education. 1999a. Ishinomoto Iseki-gun II (The Ishinomoto Site II). Kumamoto Kumamoto Prefocture Board of Education.

Kumamoto Prefocture Board of Education. 1999b. Mimikiri Iseki (The Mimikiri Site). Kumamoto: Kumamoto Prefocture Board of Education.

Kumamoto University. 2000. Koukogaku Kenkyu-shitsu Hokoku dai 35 shu (The Archaeological Report, Kumamoto University Vol. 35). Kumamoto: Kumamoto University.

Minami Tane Town Board of Education. 1993. Yokomine Iseki (The Yokomine site). Kagoshima: Minami Tane Board of Education.

Minami Tane Town Board of Education. 2000. Yokomine C Iseki (The Yokomine C Site). Kagoshim: Minami Tane Board of Education.

Nagano S. 2000. Kyusekki Jidai no Jintai-gata Sekiseihin-Mimitori Iseki (The Stone Figurine of the 
Paleolithic Period Recovered from the Mimitori Site). Kokogaku Janaru 467:27-9.

Nakamura T, Tsuji S, Toizumi G, Tsumura H, Harunari $\mathrm{H}$, editors. $2000 .{ }^{14} \mathrm{C}$ ages of the Japanese prehistory. Tokyo: Japan Association for Quaternary Research.

Naka Tane Town Board of Education. 1999. Kyozuka Tachikiri (Kyozuka Tachikiri). Kagoshima: Naka Tane Town Board of Education.

Obata H, Eiji M. 1999. Kyushu-chihou/Nansei-shoto (Kyushu Region and Southwest Archieplago). Kyusekki Kokogaku 58:58-63.

Oda S. 1999. Ryukyu Retto Kyusekki Bunka no Waku Gumi ni tsuite (Marginal Zone: Upper Paleolithic Cultures around the Ryukyu Islands). Jinruishi Kenkyu 11:29-46.

Okamura M. 1998. Rekishi Hakkutsu 1 Sekki no Seisui (Study of history 1: development and decline of lithics). Tokyo: Kodan-sha.

Okamura M. 2000. Nihon no Rekishi 10 Jomon no Seikatsu-shi (History of Japan 10: Life in the Jomon Period). Tokyo: Kodan-sha.

Omoto K. 1999. Bunshi-Jinrui-gaku kara mita Nihonjin no Kigen (Origin of Japanese: molecular biological perspective). In: Sahara M, Tanaka M, editors. Kodaishi no Ronten 6. Tokyo: Shogakkan. p 39-70.

Omoto K, Saitou S. 1997. Genetic origins of the Japanese: a partial support for the "dual structure hypothesis". American Journal of Physical Anthropology 102:437-46.

Serizawa C. 1976. The Stone Age of Japan. Asian Perspectives XIX(1):1-14.

Serizawa C. 1979. The Paleolithic Age of Japan. Paper presented for the Richard K Beardsley Symposium on Japanese Archaeology and Prehistory, at the Center for Japanese Studies, the University of Michigan, Ann Arbor, Michigan.

Shimaoka T. 2000. Miyazaki-ken Jito-gun Kawaminami- cho Ushiromuta Iseki no dai1 4ji chosa ni tsuite (On the excavation of the first to fourth excavation field years at the Ushiromuta site, Kawakmimami-cho, Jito-gun, Miyazaki). In: Kyushu Bunka Kenkyukai, editor. Kyushu niokeru Koki Kyusekki Jidai Bunka no Seiritsu. Kumamoto: Kyushu Kyusekki Bunka Kenkyu Kai. p 9-11.

Suzuki H. 1975. Discoveries of the Fossil Man from Okinawa Island (in Japanese). Journal of the Anthropological Society of Nippon 83(2):113-24.

Tachibana M. 2000. Kyushu ni okeru Chuki Kyusekki Jidai to Kouki Kyusekki jidai Seiritsu zengo no Sekkigun (The lithic complex during the Middle Paleolithic and emerging period of the Upper Paleolithic in Kyushu). Beppu Daigaku Hakubutsu kan Kenkyu Hokoku 20:1-33.

Takamiya H. 1983. Okinawa no Kodai Bunka wo megutte (On the ancient culture in Okinawa). In: Obayashi T, Tanigawa K, Mori K, editors. Okinawa no Kodai Bunka. Tokyo: Shogakkan. p 59-86.

Takamiya H. 1994. Okinawa no Senshi Iseki to Bunka (Archaeological Sites and Cultures in Okinawa). Tokyo: Daiichi Shobo.

Takamiya H. 1996. Initial colonization, and subsistence adaptation processes in the late prehistory of the island of Okinawa. Indo-Pacific Prehistory Association Bulletin 15:143-50.

Tamura K, Ikeda O. 1995. Kishikawa Iseki (Kishikawa Site). Aoyama Shigaku 14:1-64.

Tokunaga S. 1936. Bone artifacts used by ancient man in the Ryukiyu Islands. Proceedings of the Imperial Academy XII(10):352-4.

Turner C II. 1987. Late Pleistocene and Holocene population history of East Asia based on dental variation. American Journal of Physical Anthropology 73:30521. 